\title{
Alternative energy storage options for Heat Pump Water Heater coupled with photovoltaic plant for Domestic Hot Water production

\author{
Marco Beccali ${ }^{1}$, Giuliana Leone ${ }^{1}$, Gaetano Zizzo ${ }^{1}$, Marina Bonomolo ${ }^{1}$ \\ Biagio Di Pietra², Francesco Monteleone ${ }^{2}$ \\ ${ }^{1}$ Università degli Studi di Palermo, Palermo (Italy) \\ ${ }^{2}$ ENEA, Palermo (Italy)
}

\begin{abstract}
The present work relies on the topic of energy storage for Heat and Electricity applied to Heat Pump Water Heaters coupled with photovoltaic plants for Domestic Hot Water production. The main idea is to evaluate the possibility to exploit the water tank as heat storage for the produced photovoltaic energy and, where appropriate combined with electrical storage. For this reason, two heat pumps with different volume size have been chosen and smart control strategies have been applied while monitoring the water temperature in the tank. Calculations account on tapping profile inferred from monitored data of a representative end-user in a Mediterranean small island. Results show how the combination of smart control strategies and battery systems is the most suitable solution in order to fulfil the domestic hot water energy demand by renewable sources while maintaining comfort requirements.
\end{abstract}

Keywords: small islands, RES storage, power-to-heat, electric storage, thermal storage, smart control

\section{Introduction}

At state of the art, an essential challenge in renewable energy sources (RES) panorama is to make energy production able to meet energy demand in time and quantity. According to this issue, the energy storage system plays an important role by contributing to smooth the renewable resource's intermittency enabling the meeting between energy demand and supply. Many research works have been carried out during the last decade exploring different options for storing the produced energy. As an example, Marczinkowski and Østergaard (2019) identified two possible approaches to the problem focusing on Northern Europe Small Islands (Samso, Denmark and Orkeney, UK): investing on battery energy storage systems or converting renewable electricity into heat implementing the use of thermal storage. Both islands share similar energy scenario in which part of the island's household are connected to biomass-based district heating (DH) while wind power plants provide the most of the electricity production. It has been stated that the use of Thermal Energy Storage (TES) coupled with a heat pump (HP) system leads to different advantages: maximum RES exploitation as well as reduced economic and environmental costs for biomass transportation. Nevertheless, the same authors successively extend this study focusing on economic and social aspects (Østergaard et al., 2019). They outlined a gap between collective and plant operator perspectives that has to be overcome. Similarly focused on DH, Schweiger et al. (2017) investigate the possibility to exploit the power-to-heat potential of electric boilers in order to fulfil the gap between renewable energy production and demand. It is worth to note that they define the surplus energy production by RES plants as a "negative residual load" to be employed in the system. These studies focused on communities that are actually connected to the mainland grids with the aim of minimizing their dependence on grid reliability. It has to be noticed that if storage systems play an important role in such circumstances, they are of primary interest in isolated communities such as those of some small islands.

Indeed, most of the small islands worldwide are generally not connected to the mainland electric power or naturalgas grids. Consequently, their energy supply system is onsite and mainly relies on imported fossil fuel, although renewable energy sources are available within their territories (Kuang et al., 2016) (Favuzza et al., 2011). Indeed, physical, climatic and socio-economic barriers could influence RES exploitations (Meschede et al., 2016). From a technical point of view, it has mainly been noticed that RES intermittence production in an isolated system could be regarded as a barrier to let them spread. It has also been demonstrated that only a relevant penetration of storage technologies could increase RES diffusion in the energy supply system (Duic' et al., 2008). Some studies then proposed multipurpose and more resilient systems including trigeneration plant that can fulfil energy demand as well as freshwater request using the extra-produced power in desalination units (Calise et al., 2016). Most recent 
researches focused on the integration of batteries and hydrogen storage, considering the possibility to use the produced hydrogen to drive fuel cell electric vehicles and hydrogen compressed natural gas (Groppi et al., 2018). Additionally, seawater pumped hydro storage have been analyzed as an alternative to electrochemical storage system reaching a 100\% RES penetration in some Greek Islands (Katsaprakakis et al., 2019). The proposed studies mainly relies on a large plant (photovoltaic and/or wind turbine), even if it is frequently local landscape regulations could sometimes inhibit this kind of installation (Ciriminna et al., 2016). On the other hand, large-scale retrofit strategies such as converting the existing diesel engines into district heating/cooling plants have been proven to be moderately economical attractive in Mediterranean climate especially when no-public support is available (Beccali et al., 2017a).

Same attention must be dedicated to the demand side. For this reason, the present paper proposes a study on retrofit strategies applied at the residential Domestic Hot Water (DHW) demand in the Island of Lampedusa in Italy $\left(35^{\circ} 30^{\prime} 56^{\prime \prime} \mathrm{N} 12^{\circ} 34^{\prime} 23^{\prime \prime} \mathrm{E}\right)$. Specifically, it focuses on PV-based heat pumps systems locally installed on the roof. Indeed, it has been demonstrated how the current widespread Electric Storage Water Heater (ESWH) strongly influences the consumers' overall electrical consumption as well as the peak in the daily power demand in the island (Beccali et. al, 2017b). The main idea is to evaluate, the possible options of thermal and/or electric storage in exploiting the PV-produced energy at a single-house level. Finally, DHW consumption is strongly influenced by cultural and socio-economic factors and generally undergoes seasonal fluctuation due to climatic condition (Fuentes et al., 2018). The authors underlined the importance of using proper values and hourly tapping profile for specific context more than standard values from regulation, for this reason, present work relies on processing data from an experimental campaign aimed at identify appropriate values for a representative end-user in the Island.

\section{Methodology}

In the current paper, the results of dynamic simulations of different plants and control logics applied to the DHW demand and coming from an actual case study are presented and discussed. DHW consumptions were monitored for a typical domestic end-user in Lampedusa Island (Italy) whose hot water energy need is provided by a $1200 \mathrm{~W}$ ESWH. According to the Italian national statistical database, the selected end-user is a representative family composed of two members living in $150 \mathrm{~m}^{2}$ two-floors dwelling. The experimental campaign was performed during the summer period and involved both the overall electrical consumption of the house and the specific ESWH consumption, with 15-minute time-step (Beccali et. al, 2017b).

Average hourly data were evaluated distinguishing weekdays from Saturday/Sunday values. Recorded values were then correctly arranged in order to meet EN 12831-3:2018 requirements:

$m_{D H W, h}=x_{h} V_{D H W, d a y}$

(eq. 1)

where $\mathrm{m}_{\mathrm{DHW}, \mathrm{h}}$ is the volume of DHW drawn at the time $\mathrm{h}$ and $x_{h}$ is the relative amount of DHW consumed at a specified hour with respect to the daily amount $\left(\mathrm{V}_{\mathrm{DHW} \text {,day }}\right)$. Since only electrical consumption data are available from the experimental campaign the following assumption was introduced for evaluating $x_{h}$ : ESWH electric consumption is evidence of tapping events excluding values below $120 \mathrm{Wh}$ that are supposed to be scattered events due to thermostat input.

$x_{h}$ is consequently calculated by analyzing the ESWH data from monitoring campaign:

$x_{h}=E_{D H W, h} / E_{D H W, d a y}$

where $\mathrm{E}_{\mathrm{DHW}, \mathrm{h}}$ is the ESWH consumed energy at the time $\mathrm{h}$, and $\mathrm{E}_{\mathrm{DHW} \text {,day }}$ is the daily one. $x_{h}$ trend together with collected daily data were also suitable to check the summer average-daily hot water consumption $\left(\mathrm{V}_{\mathrm{DHW} \text {,daily-summer }}\right)$ by means of a calibration routine of the actual ESWH simulation model implemented on the TRNSYS platform. The latter simulates the thermal behavior of the DHW tank (type 1237) at fixed set point temperature $\left(60^{\circ} \mathrm{C}\right)$ by a thermostat (type 2) driving on/off cycles of the electrical resistance (type 1226). Temperature of water from the local network was assumed to be equal to ground temperature at $2 \mathrm{~m}$ depth, while hourly DHW taps were calculated according to Eq. 1, changing one at time the $\mathrm{V}_{\mathrm{DHW} \text {,day }}$ until daily results correctly match the average recorded value, determining a daily DHW summer consumption for the reference user. In order to broaden results all year long, some multiplication factors calculated from the end-user electrical bills $\left(\mathrm{E}_{\mathrm{bill}}\right)$ were applied. The estimated end-user tapping volume $\left(\mathrm{m}_{\mathrm{DHW} \text {,day }}\right)$ has been successively applied to retrofit scenarios where a dedicated Heat Pump Water Heater (HPWH) substitutes the actual electrical system. An all-in-one air-to-water HP technology has been chosen and two different systems (HPWH-200 and HPWH-100) having different sizes of 
water storage (200 and 100 liters) have been selected among the available products in the market (main features are reported in Tab. 1). HPWH consumption and thermal behavior were also evaluated by a TRNSYS model in which the performance curve of the plant component has been assessed by a validation routine with respect to nominal data in Tab. 1, according to test condition in EN 16147:2017.

Tab. 1: Heat Pump Water Heater technical data

\begin{tabular}{|c|c|c|c|}
\hline \multicolumn{2}{|c|}{ Feature } & HPWH-200 & HPWH-100 \\
\hline Electric Nominal Power & {$[\mathrm{W}]$} & 490 & 250 \\
\hline Standard Tapping Profile & {$[-]$} & $\mathrm{L}$ & $\mathrm{M}$ \\
\hline COP DHW (A15/W10-55) & {$[-]$} & 3.07 & 3.10 \\
\hline Air flow rate at nominal condition & {$\left[\mathrm{m}^{3} \mathrm{~h}^{-1}\right]$} & 450 & 165 \\
\hline Water Tank Volume & {$[$ liter $]$} & 208 & 80 \\
\hline Maximum water temperature with heat pump & {$\left[{ }^{\circ} \mathrm{C}\right]$} & 65 & 55 \\
\hline
\end{tabular}

Taking into account the nominal compressor electrical power in Tab.1, two different grid-connected PV plants able to nominally fit compressor requirements (with respects to technical features for the most common market availably PV panel) are designed (720 $\mathrm{W}_{\mathrm{p}}$ for the HPWH-200 and $480 \mathrm{~W}_{\mathrm{p}}$ for the HPWH-100 models) by assembling monocrystalline panels with $240 \mathrm{~W}_{\mathrm{p}}$ and $14.6 \%$ electrical efficiency (Fig. 1). In both cases the PV panels are oriented toward South. Moreover, according to present work purposes and considering mean daily HPWH electrical consumption by results from TRNSYS model, a suitable battery system is provided.

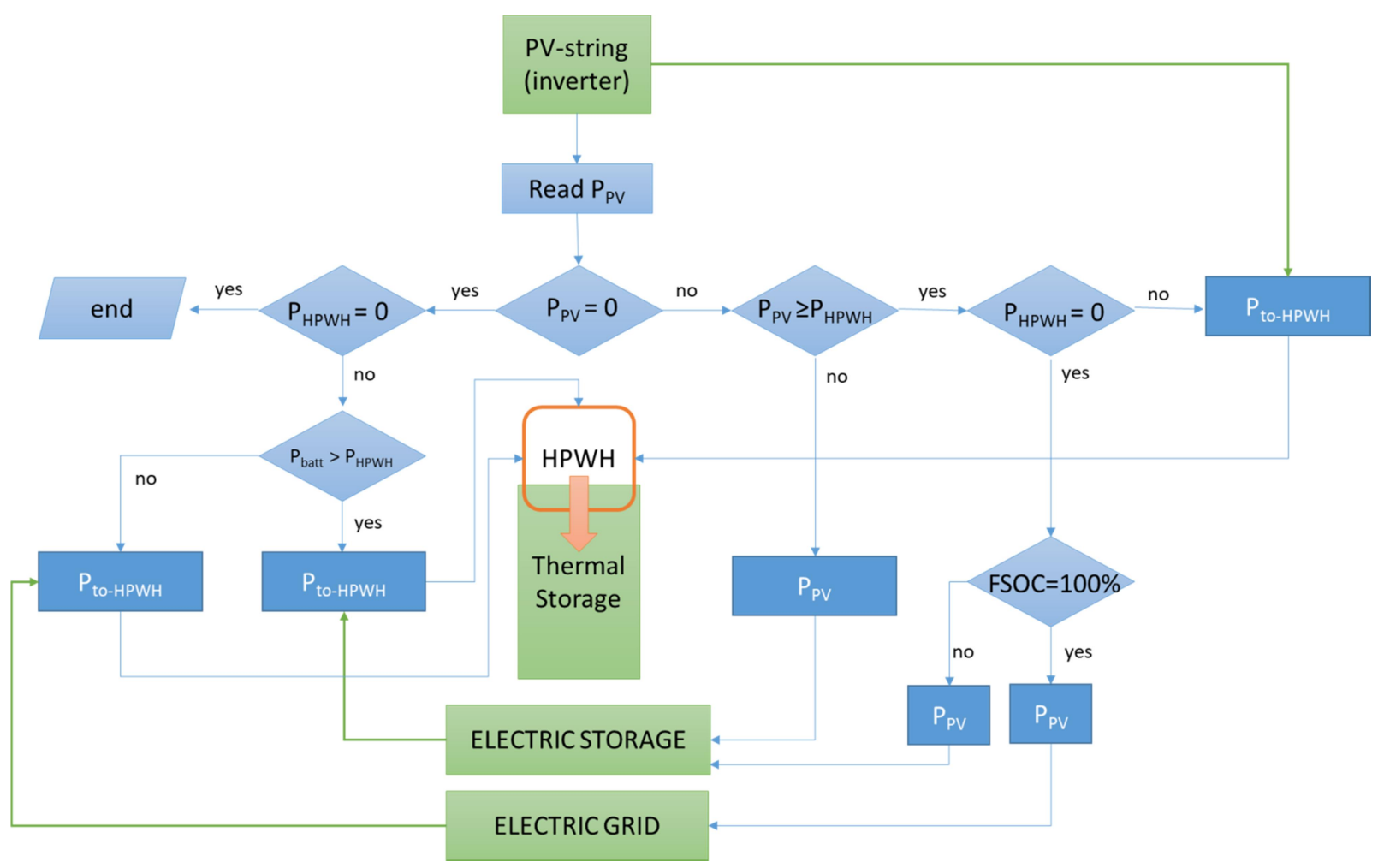

Fig. 1: DHW Plant workflow

Three management strategies for optimizing the energy saving for the hot water production have been consequently introduced. It resulted in the definition of three scenarios that have been utilized for dynamic simulations: 
- Scenario 1. ON/OFF control by a thermostat with steady set point temperature according to the value in Tab. 1 and 1200 Wh electrical storage available;

- Scenario 2. ON/OFF smart control by thermostat with variable set point temperatures aimed to optimize the utilization of RES plant production. Maximum temperature values are allowed whenever produced PVenergy fits $\mathrm{HPWH}$ nominal power $\left(65^{\circ} \mathrm{C}\right.$ for $\mathrm{HPWH}-200$ and $55^{\circ} \mathrm{C}$ for $\left.\mathrm{HPWH}-100\right)$. Otherwise, tank temperature is fixed at an intermediate value $\left(\mathrm{T}_{\mathrm{i}}\right)$ equals to $55 \pm 2{ }^{\circ} \mathrm{C}$ and $50 \pm 2{ }^{\circ} \mathrm{C}$ (respectively for HPWH-200 and HPWH-100) whenever the electrical storage is usefully charged and some tapping occurs; or else set point temperature sets at $45 \pm 2{ }^{\circ} \mathrm{C}$ (Fig. 2).

- Scenario 3. ON/OFF smart control as previous described without electrical storage available in the system (Fig. 2).

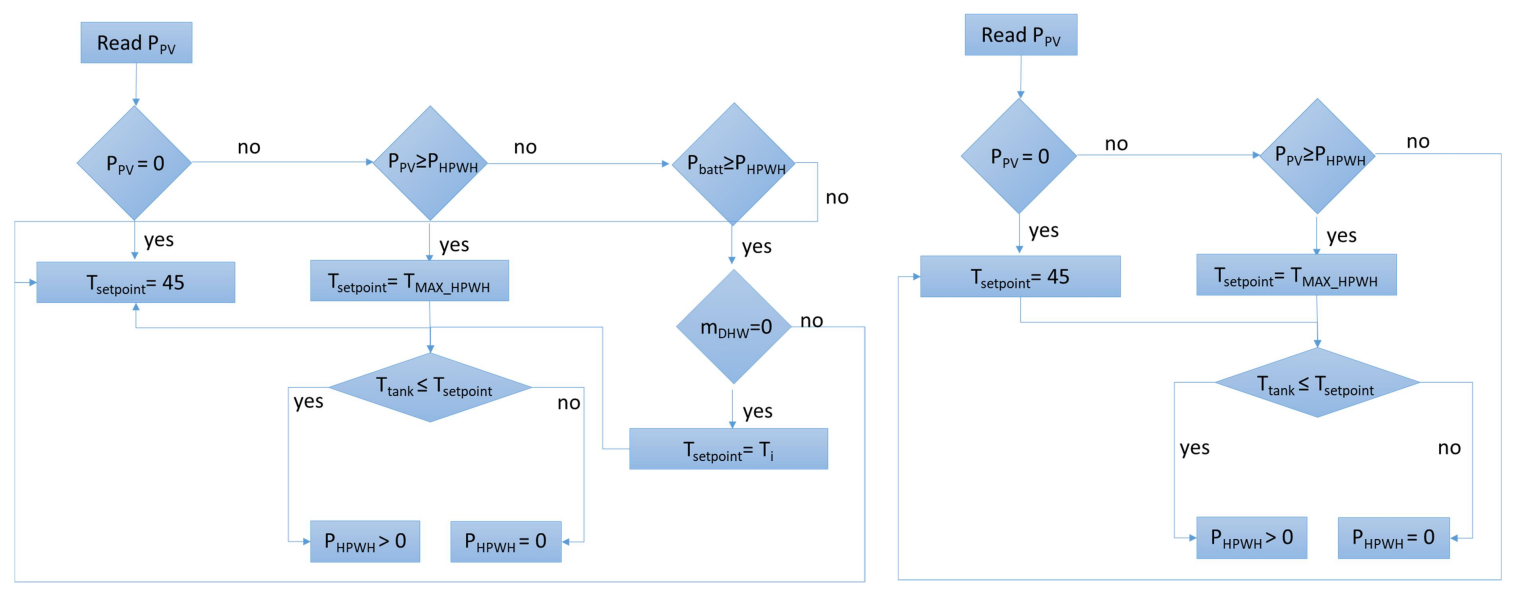

Fig. 2: Smart control strategy in Scenario 2 (left) and Scenario 3 (right)

Results obtained by the TRNSYS model were processed and the following indexes evaluated:

$$
\begin{aligned}
& A_{R E S}=\frac{E_{\text {to-load }}}{E_{H P W H}} \\
& A_{C}=\frac{E_{P V}}{E_{H P W H}} \\
& C I=1-\sum_{i=1}^{h} \frac{\text { n.hou }_{T \_D H W 40}}{\text { n.hour }_{\text {tot_1 }}} \\
& P D I=\sum_{i=1}^{h} \frac{\text { n.hour }_{T_{\_} D H W 40}}{\text { n.hour }_{\text {tot } 2} 2} \\
& \text { FSOC }_{\text {av }}=\frac{E_{\text {battery }}}{E_{\text {battery,max }}}
\end{aligned}
$$

where $\mathrm{E}_{\text {to-load }}$ is the PV energy delivered to the HPWH, $\mathrm{E}_{\mathrm{HPWH}}$ is the heat pump electrical consumption, $\mathrm{E}_{\mathrm{PV}}$ is the PV produced energy, $\mathrm{T}_{\mathrm{DHW}}$ is the tank temperature. Moreover, considering an examined period: $n$.hour $\mathrm{T}_{\mathrm{T}} \mathrm{DHW} 40$ in eq. 5 is the number of hours in which $\mathrm{T}_{\mathrm{DWH}}$ drops below the desired comfort temperature $\left(40^{\circ} \mathrm{C}\right)$ during tapping event (n.hour $\mathrm{tot}_{1}$ ) otherwise in eq. 6 it is the number of hours in which $\mathrm{T}_{\mathrm{DWH}}$ drops below the desired comfort temperature during no-tapping events (n.hour ${ }_{\text {tot_2 }}$ ), $\mathrm{E}_{\text {battery }}$ is the average monthly/yearly value of the stored energy in the battery and $E_{\text {battery,max }}$ is the nominal battery capacity. The first two indexes were suitable to evaluate the way PV-plant interacts with the load, checking for energy availability from the whole system including battery ( $\left.A_{\text {RES }}\right)$ and for the contemporaneity between suitable production from PV panel and load requirements $\left(\mathrm{A}_{\mathrm{C}}\right)$. CI (Comfort Index) and PDI (Potential Discomfort Index) have been introduced in order to check if the smart control strategies in Scenario 2 and 3 are able to meet the comfort condition sets at $\mathrm{T}_{\mathrm{DHW} \text {-comfort }} \geq 40{ }^{\circ} \mathrm{C}$ during tapping events (CI) and no-tapping events (PDI). FSOC $_{\mathrm{av}}$ (Fractional State of Charge) is the average value in a defined period of the state of energy charge in the battery used to evaluate the way the storage is used.

Eventually, cost of both HPWH-2000 and HPWH-100 systems have been estimated and the Net Present Value (NPV) evaluated as: 
$N P V=-C_{0}-\sum_{t=1}^{n}\left(\frac{(S+I+E-M)}{(1+i)^{t}}\right)$

where $\mathrm{C}_{0}$ is the initial cost, $\mathrm{S}$ and I are respectively the yearly economic saving for energy consumption due to the substitution of the actual system with a higher efficiency one, $\mathrm{M}$ is the maintenance cost, I the incentive for $\mathrm{HPWH}+\mathrm{PV}$ installation by Italian government distributed in 10 years according to legislation in force, E is surplus PV produced energy sell back to grid and $i$ is the interest rate of money. HPWH initial and maintenance cost have been inferred in Kemna (2019) while PV plant costs refers to Italian market analysis.

The NPV is estimated at the end of the useful life of the whole system $\left(\mathrm{t}_{\mathrm{eq}}\right)$. The latter is calculated according to Italian guidelines PREPAC by the Italian National Agency for New Technologies, Energy and Sustainable Economic Development (ENEA):

$t_{e q}=\frac{\sum C_{0, i}}{\sum C_{o, i} k_{i}} t_{\max }$

where $i$ stays for the generic component of the plant, $t_{\max }$ is the maximum life time observed among plant components and $k_{i}$ is the ratio between $t_{\max }$ and the life time for the generic component. Specifically according to ENEA guidelines PV plant and HPWH life time is estimated respectively at 20 years and 15 years.

\section{Results}

Monitored data on ESWH energy consumption were processed according to the described method. Fig. 3 shows the daily consumption; it is worth to note that the ESWH electrical consumption is averagely $30 \%(2.1 \mathrm{kWh} /$ day $)$ of the overall electric consumption differing from $15 \%$ to $48 \%$.

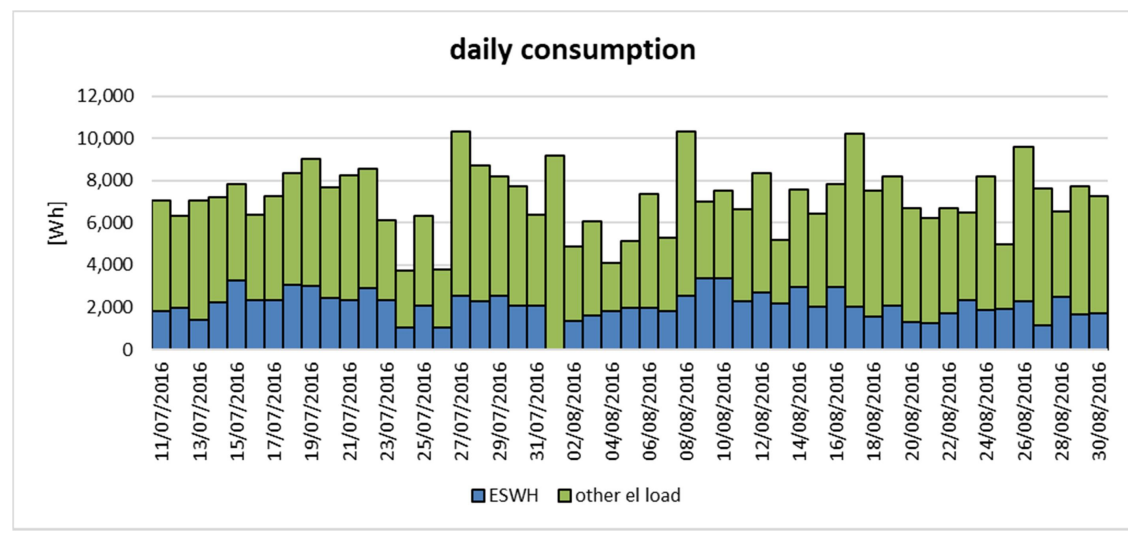

Fig. 3: Daily user electrical consumption

Average hourly data are plotted in Fig.4. Since no significant differences between weekday and weekends daily trends are outlined, average hourly figures in the monitored period are considered as reference for finding out the $\mathrm{x}_{\mathrm{h}}$ trend by eq. 2 . At the same time, bi-monthly electrical consumption data from bills (Fig. 3) were processed for

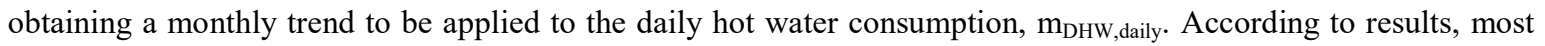
of the DHW consumption occurs during afternoon/evening hours with a peak at $16: 00,24 \%$ of the detected daily $\mathrm{m}_{\text {DHW,daily. }}$

The described TRNSYS ESWH model was then launched several times using the obtained tapping series and changing one at a time the $\mathrm{m}_{\mathrm{DHW} \text {,daily-summer }}$ value since the consumption simulated daily result matches the recorded mean value. The model simulates a $1200 \mathrm{~W}$ ESWH at fixed set point temperature $\left(60 \pm 3^{\circ} \mathrm{C}\right)$ obtaining 90 liters/day result with a relative error between monitored electrical consumption and simulation results equals to $7 \%$ (both evaluated at time step $15 \mathrm{~min}$ ). Following the described method, the hot water daily consumption varies from 80 liters/day in September/October to 147 liters/day in January/February. 

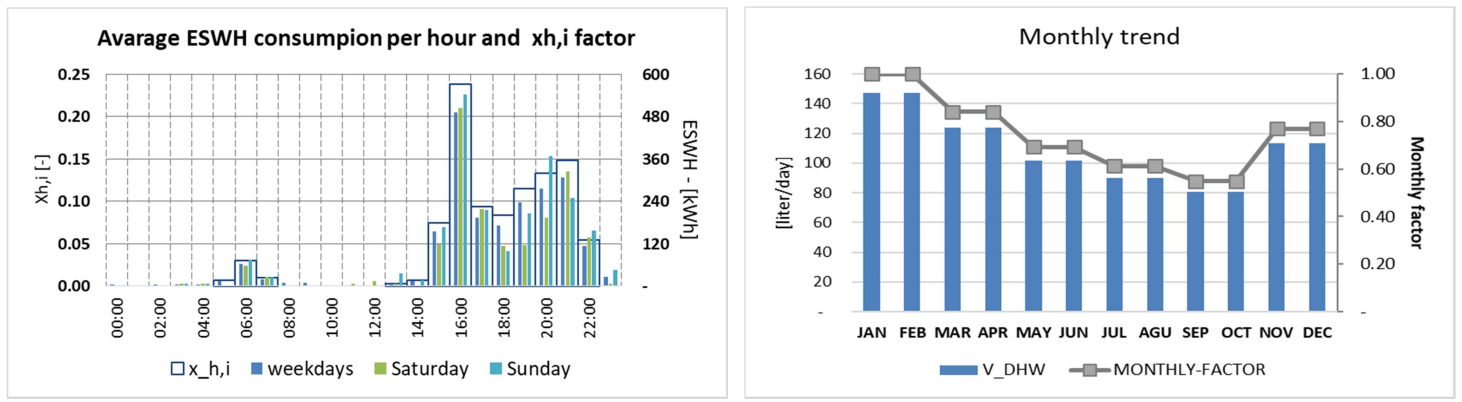

Fig. 4: On the left, hourly tapping from monitored data; on the right monthly factor.

The obtained tapping profile consequently follows the same hourly trend all year long while DHW daily volume varies month by month. This Tapping is used as input in the HPWH TRNSYS model finding out the following results.

Heat Pump consumption in Scenario 1 (Fig. 5) with steady-state set-point temperature is about $365 \mathrm{kWh} / \mathrm{year}$ without any additional electrical resistance operation, achieving a $65 \%$ of energy saving goal with respect to the existing ESWH system (1,072 kWh/year). Slightly differences between HPWH-100 and HPWH-200 monthly consumption are outlined and are mainly due to their different thermal capacities and set-point base temperatures. It is worth to note that during a typical winter day, the differences in the thermal capacities between 100 and 200 liter tanks, being the tapping equals in both simulation, influences the on/off cycle of the two analyzed system (Fig. 5). Peak load for HPWH-200 are gathered in the morning while HPWH-100 shows two peaks most related to tapping events. Moreover, the imposed $\mathrm{m}_{\mathrm{DHW} \text {,daily }}$ monthly trend and the water main temperature variation according to type 77 correctly influence the energy consumption all year long. The 480 and $720 \mathrm{Wp}$ PV plants are able to produce respectively 957 and $1435 \mathrm{kWh}$ per year.
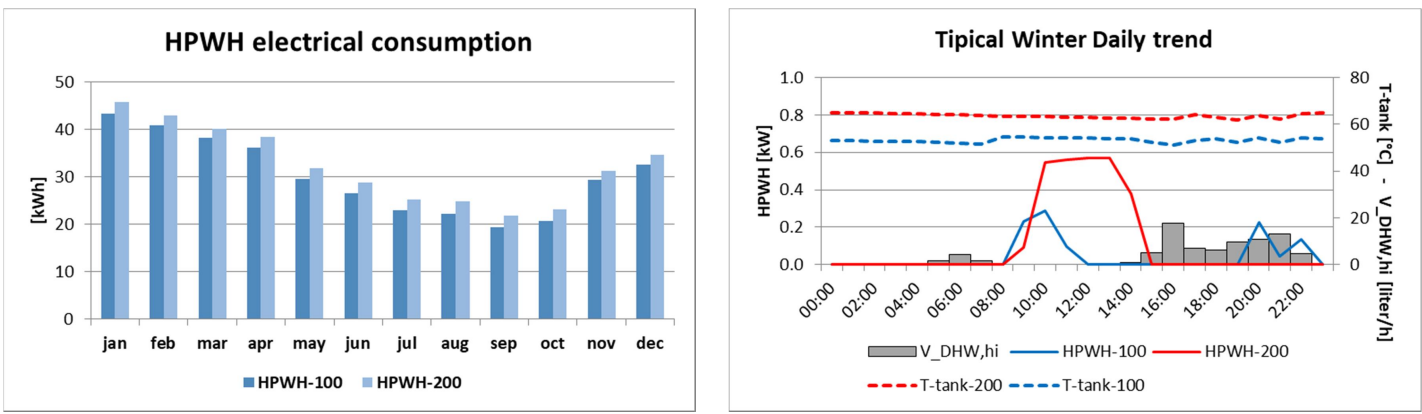

Fig. 5: on the left, HPWH monthly electrical consumption comparison; on the right, tank temperatures and HP power with respect to tapping profile

Scenario 2 and Scenario 3 both include a smart control on the on/off HP cycles by varying set point temperatures in function of the PV-plant power availability. It is worth to note that some consumption reduction due to smart control occur for both systems in Scenario 2 and 3 with respect to Scenario 1: it is of slight interests (3.5\%) for Scenario 2 but assume most relevance in Scenario $3(10 \%)$ even if it goes to the detriment of comfort. At this regards, it is important to consider that the higher thermal capacity of HPWH-200 limits discomfort conditions that could be assumed as almost negligible in both Scenario 2 and 3. On the other hand, HPWH-100 working at conditions of Scenario 3 shows high discomfort values that could be considered unacceptable by users (Fig. 6). 

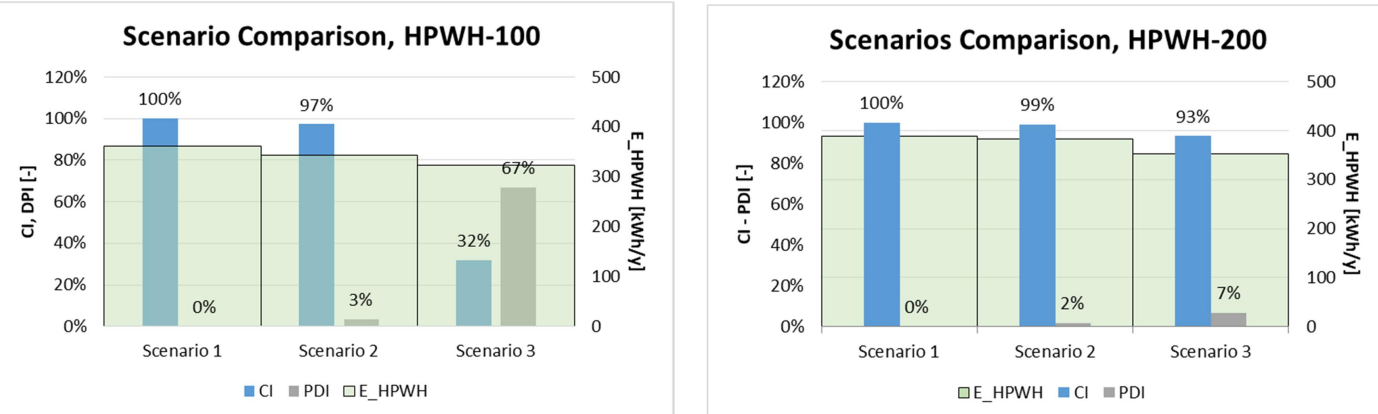

Fig. 6: Comfort indexes: on the left, HPWH-100 - on the right, HPWH-200

Aside from the reduction of energy consumption due to the smart thermostat control, it is worth to note how PVplant interacts with the HP load (Fig. 7). For both HPWH-100 and HPWH-200, the conjunction of smart control and electrical storage (Scenario 2) leads to $\mathrm{A}_{\mathrm{RES}}$ index almost equals to $100 \%$, meaning that PV-plant definitively covers all DHW need. On the other hand, excluding the smart control on the thermostat (Scenario 1) or excluding the battery storage (Scenario 3 ) involve yearly $A_{\text {RES }}$ index values respectively equals to $92 \%$ and $50 \%$ for HPWH100 and $89 \%$ and $65 \%$ for HPWH-200.
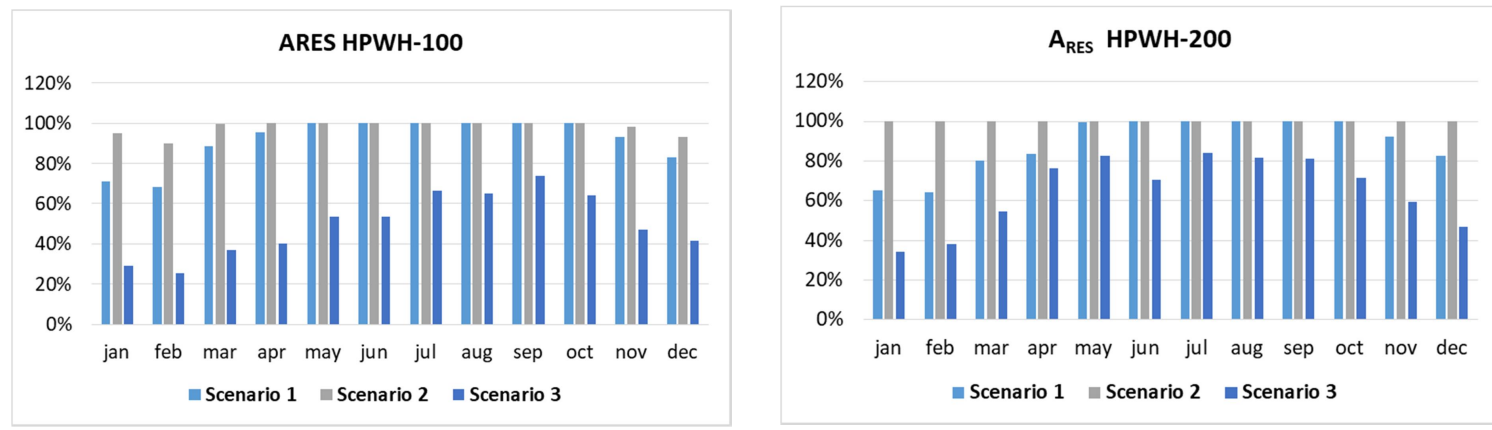

Fig. 7: ARES index in different Scenarios: on the left, HPWH-100; on the right, HPWH-200

Other remarkable results concern the role the electrical storage plays in the analyzed systems at different working conditions. It has to be first noted that simulations for Scenario 2 and 3 leads to $A_{C}$ values that logically increase with respect to Scenario 1. It is because the system is forced to work rising up the set point temperature whenever $\mathrm{PV}$ produced energy is adequate to drive the heat pump cycle, Tab.3. Consequently, the yearly average FSOC $_{\mathrm{av}}$ increases for both Heat Pump models meaning the electrical storage plays a partial role in the system, overall for HPWH-200.

\begin{tabular}{|c|c|c|c|c|c|c|}
\hline \multirow{2}{*}{ Indexes } & \multicolumn{2}{|c|}{ Scenario 1 } & \multicolumn{2}{c|}{ Scenario 2 } & \multicolumn{2}{c|}{ Scenario 3 } \\
\cline { 2 - 7 } & HPWH-100 & HPWH-200 & HPWH-100 & HPWH-200 & HPWH-100 & HPWH-200 \\
\hline $\mathrm{A}_{\mathrm{C}}$ & $9 \%$ & $12 \%$ & $44 \%$ & $58 \%$ & $50 \%$ & 68 \\
\hline FSOC $_{\mathrm{av}}$ & $49 \%$ & $49 \%$ & $64 \%$ & $82 \%$ & Not applicable & Not applicable \\
\hline
\end{tabular}

Indeed, Fig. 8 (HPWH-200) and Fig.9 (HPWH-100) show the system daily behavior for Scenario 2 in representative winter and summer days that were chosen according to radiation daily median value in the most critical months (December and August). For HPWH-200 (Fig. 8), the smart control on the set point temperature together with the maximum achievable temperature by heat pump cycle and together with the larger tank volume allows obtaining the desired effect. The HPWH switches on only when PV energy is available. Nonetheless, it has been observed that on a yearly basis some dependence on the battery is recorded for maintaining set point temperature. It explains how in Scenario 3, where no electrical storage is provided, some discomfort condition is recorded for the chosen smart control on set-point temperature.

On the other hand, HPWH-100 shows higher electrical storage dependence, Fig. 9. In this case, it has to be considered that the maximum achievable temperature $\left(55^{\circ} \mathrm{C}\right)$ limits the effect of the smart logic. Moreover, the reduced tank volume restricts the possibility to store the produced PV energy as thermal one. For all these reasons HPWH-100 switches on mainly in conjunction with tapping events, occurring in the morning and in the evening, 
exploiting the stored energy.

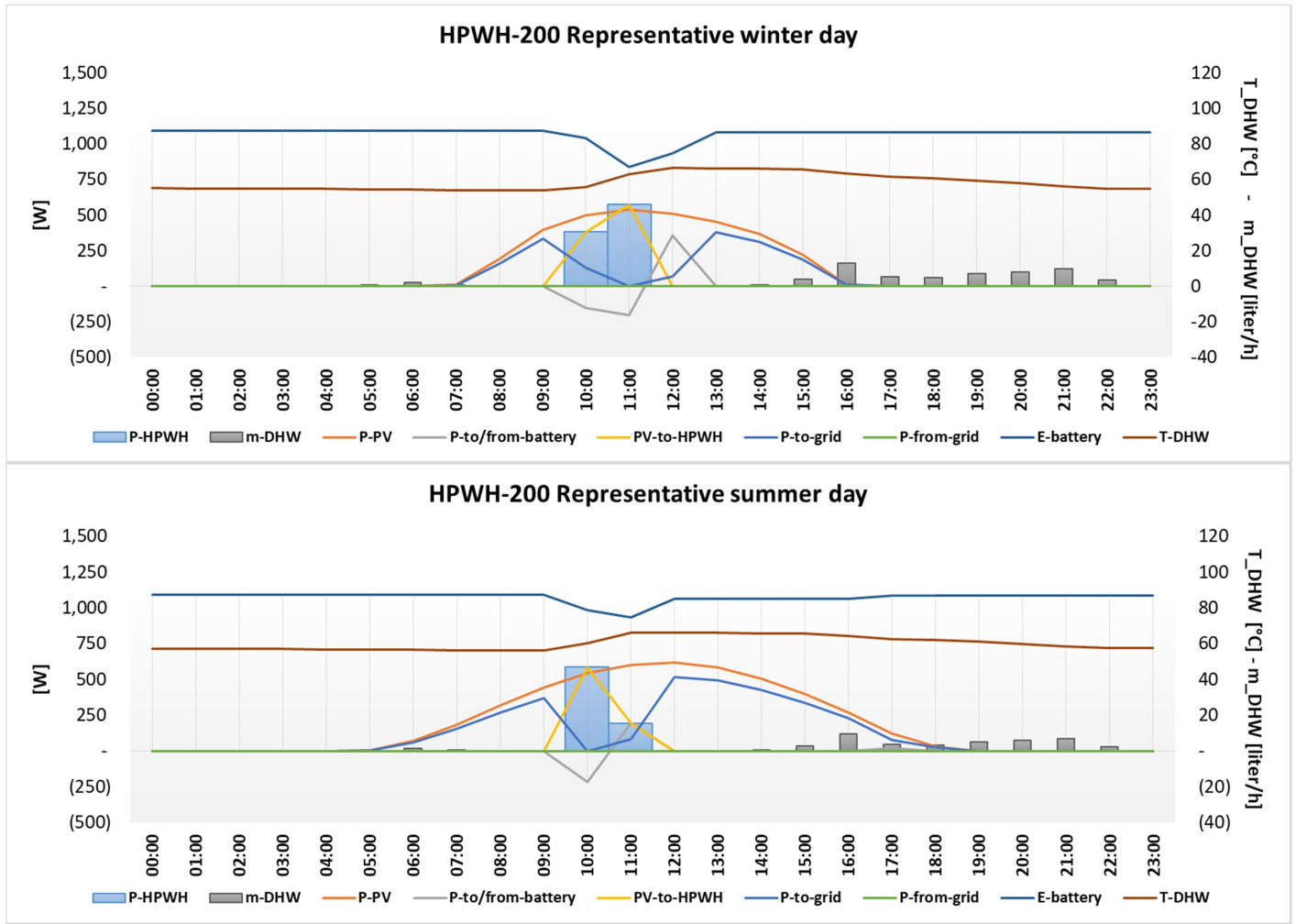

Fig. 8: Daily trend, Scenario 2 - HPWH-200

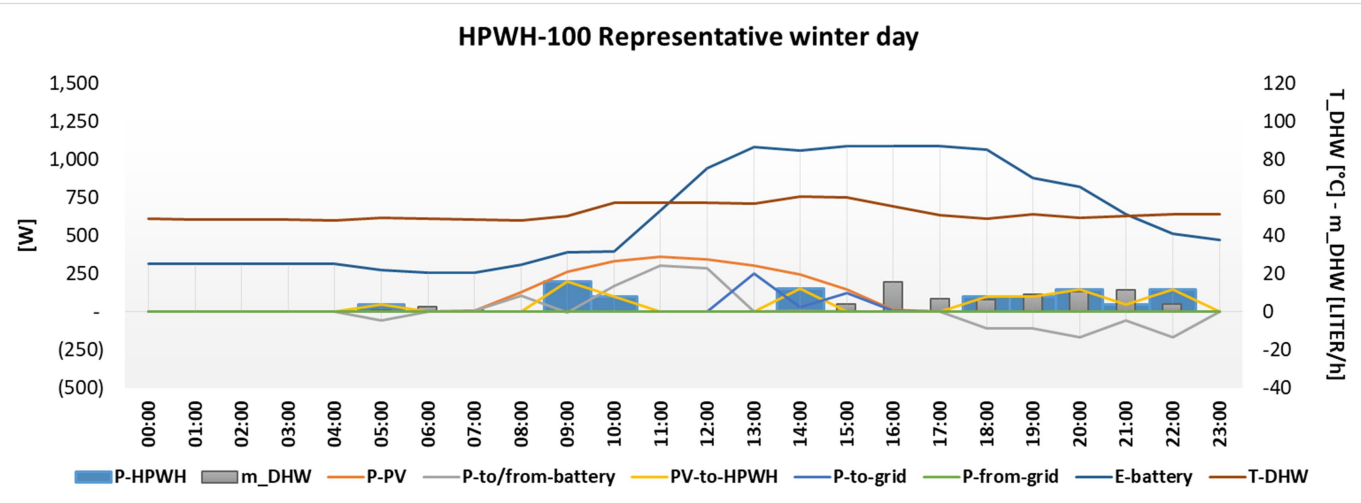

HPWH-100 Representative Summer day

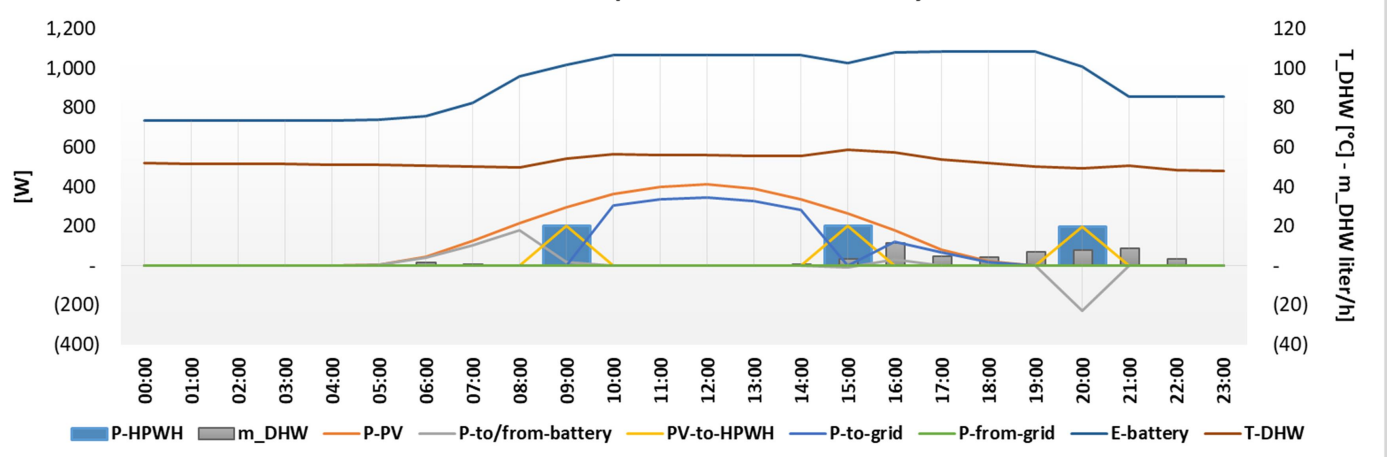

Fig. 9: Daily trend of the system, Scenario 2- HPWH-100 
Economic analysis was performed for the two plants. According to eq. 9, a 18 years useful life-time is supposed in NPV evaluation. Considering no relevant difference exists in cost analysis for the different scenarios, only results for Scenario 1 are hereby presented in order to check for the most economically suitable solution between HPWH100 and HPWH-200 with regards to the actual ESWH boiler. Cost analysis bases on an EU Commission official report (Kemna, 2019) for the estimation of HPWH initial costs and of its ordinary maintenance cost, on market data for PV panels $(0.53 € / \mathrm{kWh})$ and an official price list by local government for the other components. PV maintenance cost include the substitution of battery once in the analyzed period. It has been estimated that the cost of HPWH-100 plant is about 3,000.00 $€$ while the cost of HPWH-200 plant is 4,500.00€. According to bi-monthly bills, it has been determined an average price per $\mathrm{kWh}$ of purchased energy from the grid $(0.23 € / \mathrm{kWh})$ while sellback price for produced energy is supposed equals to $0.10 € / \mathrm{kWh}$, according to the Italian panorama. Finally, the Italian incentive program for building energy refurbishment has been applied to NPV calculation. Consequently, a $65 \%$ and $50 \%$ discount distributed in 10 years has been applied respectively to HPWH and PV-plant. Fig. 10 shows results for both analyzed systems, it has to be noticed that due to the high level of independence from the grid, the economic saving per year is almost equal to the total amount of the ESWH energy cost. Moreover, the higher PV energy production in HPWH-200 positively influences the economic results overpassing the higher initial cost: NPV at the end of the useful-life for the two system is $2111,00 €$ versus $2206,00 €$ for the HPWH-100 systems. On the other hand, Scenario 3 shows slightly higher NPV values $2,270.54 €$ and $€ 2,309.25 €$, respectively for HPWH100 and HPWH-200 due to the fact battery costs are not included according to plant set up.
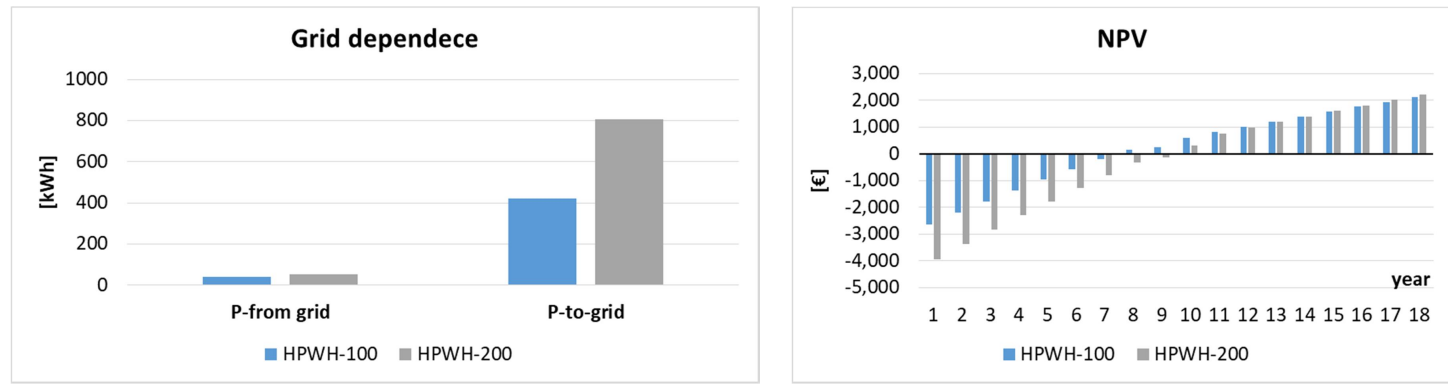

Fig. 10: on the left sell and purchased energy, on the right Net Present Value results

\section{Conclusion}

A specific tapping profile for a representative user in Lampedusa Island has been calculated from recorded data by an experimental campaign on the real ESWH system installed in an island final user place. A validated TRNSYS model was then suitable to evaluate the energy consumption of the actual system and of retrofit scenarios in which an air-to-water HPWH for DHW production substitutes the ESWH. The main idea was to evaluate the effect of thermal storage with different sizes, potentially coupled with electric storage, by applying or not smart control strategy on set point temperature.

In Scenario 1 with fixed set point temperature and 1,200 Wh electric storage, the use of the HPWH (regardless its tank size) instead of the ESWH leads to $65 \%$ energy saving goal moreover the $89 \%$ of the yearly electric consumption is covered by PV plant production. Due to the specified $\mathrm{m}_{\mathrm{DHW} \text {,daily }}$ profile, whose tapping events occur in the morning and in the evening, the contemporaneity between PV production and DHW load is obviously low (average 10\% for both heat pump models).

Scenario 2 and 3 are aimed to exploit as much as possible the tank thermal capacity as storage for the PV-produced energy. A smart control for set point temperature is introduced in the system. HPWH is forced to switch on whenever PV-produced energy is available by rising the set point temperature to its maximum achievable value, according to heat pump technical sheet.

In Scenario 2, the conjunction between smart control on set-point temperature and electric storage allows to totally fulfill the energy demand of the analyzed systems with almost negligible effects on comfort condition (ARES index sets at $100 \%$ for HPWH-200 and 98\% for HPWH-100). Due to the introduced smart control the contemporaneity between PV-production and heat pump load logically rises to $64 \%$ and $82 \%$ respectively for the 100 liters tank size and the 200 liters one. 
Scenario 3 including the smart control but excluding electric storage is the most critical in terms of comfort condition fulfillments, especially for the HPWH-100: comfort index sets at $32 \%$ while potential discomfort index is $67 \%$. Most acceptable values are recorded for the HPWH-200 (CI=93\% while PDI=3\%).

Summarizing, HPWH-200 in Scenario 2 shows the optimum solution including a $1200 \mathrm{Wh}$ battery that allows to entirely meet the heat pump energy demand by RES source while maintaining comfort condition. Moreover, some energy consumption reduction in Scenario 2 compared to Scenario $1(-4 \%)$ occurs due to variable set point temperature. It is worth to note that also from an economic point of view, HPWH-200 shows better results.

\section{Acknowledgments}

This work is mainly based on the output of the research Ricerca di Sistema Elettrico. Progetto D.1 - Analisi sperimentale e numerica di tecnologie solar driven per la climatizzazione e la produzione di ACS e di sistemi ICT per il controllo e la riduzione dei carichi elettrici nelle isole minori non connesse alla RTN (PAR 2017 - CUP I12F17000070001), funded by the Italian Minister of Economic Development and Managed by ENEA in cooperation with Università degli Studi di Palermo, Italy.

\section{References}

Beccali, M., Ciulla, G., Di Pietra, B., Galatioto, A., Leone, G., Piacentino, A. (2017a). Assessing the feasibility of cogeneration retrofit and district heating/cooling networks in small Italian islands. Energy 141, 2572-2586

Beccali, M., Bonomolo, M., Di Pietra, B., Ippolito, M.G., La Cascia, D., Leone, G., Lo Brano, V., Monteleone, F., Zizzo, G., (2017b). Characterization of a small Mediterranean island end-users' electricity consumption: The case of Lampedusa. Sustainable Cities and Society 35, 1-12

Calise, F., Dentice d'Accadia, M., Macaluso, A., Vanoli, L., Piacentino, A., (2016). A novel solar-geothermal trigeneration system integrating water desalination: Design, dynamic simulation and economic assessment. Energy $115,1533-1547$

Ciriminna, R., Pagliaro, M., Meneguzzo, F., Pecoraino, M., (2016). Solar energy for Sicily's remote islands: On the route from fossil to renewable energy, International Journal of Sustainable Built Environment 5, 132-140

Duic', N., Krajacic', G., da Graça Carvalhob, M., (2008). RenewIslands methodology for sustainable energy and resource planning for islands, Renewable and Sustainable Energy Reviews 12, 1032-1062

EN 12831-3:2018. Energy performance of buildings - Method for calculation of the design heat load - Part 3: Domestic hot water systems heat load and characterisation of needs

EN 16147:2017. Heat pumps with electrically driven compressors - Testing, performance rating and requirements for marking of domestic hot water units

Favuzza, S., Graditi, G., Ippolito, M. G., Massaro, F., Musca, R., Riva Sanseverino, E., Zizzo, G. Transition of a Distribution System towards an Active Network. Part I: Preliminary Design and Scenario Perspectives, Clean Electrical Power (ICCEP), 2011 International Conference on, July 2011.

Fuentes, E., Arce, L., Salom, J., (2018). A review of domestic hot water consumption profiles for application in systems and buildings energy performance analysis, Renewable and Sustainable Energy Reviews 81 1530-1547

Groppi, D., Astiaso Garcia, D., Lo Basso, G., Cumo, F., De Santoli, L. (2018) Analysing economic and environmental sustainability related to the use of battery and hydrogen energy storages for increasing the energy independence of small islands, Energy Conversion and Management 177, 64-76

Katsaprakakis, D.A., Dakanali, I., Condaxakis, C., Christakis, D.G., (2019) Comparing electricity storage technologies for small insular grids, Applied Energy 251113332

Kemna, R., van Elburg, M., Aarts, S., Corso, A. (2019). Final Report: Water heaters, Review study Task 2 Market analysis, Final report, available at https://www.ecohotwater-review.eu/documents.htm

Kuang, Y., Zhang, Y., Zhou, B., Li, C., Cao, Y., Li, L., Zeng, L., (2016). A review of renewable energy utilization in islands, Renewable and Sustainable Energy Reviews 59, 504-513

Marczinkowski, H.M., Østergaard, P.A., (2019) Evaluation of electricity storage versus thermal storage as part of two different energy planning approaches for the islands Samsø and Orkney, Energy 175, 505-514 
Meschede H., Holzapfel P., Kadelbach F., Hesselbach J. 2016. Classification of global island regarding the opportunity of using RES, Applied Energy 175, 251-258

Østergaard,, P.A., Jantzen, J., Marczinkowski, H.M., Kristensen, M., (2019). Business and socioeconomic assessment of introducing heat pumps with heat storage in small-scale district heating systems, Renewable Energy $139,904-914$

PREPAC, LINEE GUIDA alla presentazione dei progetti per il Programma per la Riqualificazione Energetica degli edifici della Pubblica Amministrazione Centrale PREPAC (D.M. 16 Settembre 2016) available at http://www.efficienzaenergetica.enea.it/allegati/Linee\%20Guida\%20PREPAC\%204.7.2017.compressed.pdf

Schweiger, G., Rantzer, J., Ericsson, K., Lauenburg, P., (2017). The potential of power-to-heat in Swedish district heating systems, Energy 137, 661-669 